\title{
Qualities of mathematical discourses in kindergartens
}

\author{
Per Sigurd Hundeland ${ }^{1}\left[\right.$ [ $\cdot$ Martin Carlsen ${ }^{1} \cdot$ Ingvald Erfjord $^{1}$
}

Accepted: 9 February 2020 / Published online: 21 February 2020

(c) The Author(s) 2020

\begin{abstract}
In this study we investigated qualities of the mathematical discourse in four kindergarten classes in which kindergarten teachers and 5-year-old children engaged in mathematical learning activities. We analysed differences in the mathematical discourses in two experimental kindergarten classes and two control kindergarten classes, in a research and development project. The overarching research question guiding our study was as follows: what characterises the mathematical discourse unfolding in kindergarten classes? In our study we drew on the theoretical framework Mathematical Discourse in Instruction coined by Adler and Ronda, as we quantified the collected qualitative data. Our analyses identified significant characteristics of mathematical discourse with respect to the children's opportunities to contribute with ideas and arguments. The discourse in the kindergartens differed both with respect to the extent and nature of verbal utterances among the participants, as well as the mathematical engagement nurtured amongst the children. Moreover, the mathematical discourse within the experimental kindergarten classes, to a greater extent than that in the control kindergarten classes, initiated opportunities for the participating children's mathematical learning.
\end{abstract}

Keywords Kindergarten · Mathematical discourse in instruction · Quality of mathematical discourse · Quantification of qualitative data

\section{Introduction}

The aim of our study was to reveal insights into qualities of the mathematical discourses emerging in Norwegian kindergartens. We investigated qualities of the mathematical discourse in four kindergarten classes where kindergarten teachers and 5-year-old children engaged in mathematical learning activities. Furthermore, we analysed differences in the mathematical discourses in two experimental kindergarten classes and two control kindergarten classes. The overarching research question guiding our study was as follows: What characterises the mathematical discourse unfolding in kindergarten classes? The rationale behind this research focus was the sociocultural tenet that active participation through the use of language is by far the most significant cultural tool for mediating participation and learning in sociocultural activities. A basic sociocultural stance (cf. Vygotsky 1986) is that communication is the link between internal communication (thinking) and external communication

Per Sigurd Hundeland

per.s.hundeland@uia.no

1 University of Agder, Kristiansand, Norway (interaction). Therefore, children's opportunities to contribute with ideas and arguments are vital for their (mathematical) learning processes. Kindergarten teachers (KTs) thus have to be competent in creating opportunities for children to participate in mathematical discourses. In this study we analysed mathematics teaching sessions taught by KTs who took part in a professional development programme, and mathematics teaching sessions taught by KTs without this training.

Since the launching of the Early Years Mathematics research group at the 6th Congress of the European Society for Research in Mathematics Education in 2009, about 100 research studies have been conducted. Furthermore, five POEM conferences have been arranged so far (POEM-A Mathematics Education Perspective on early Mathematics Learning). The pool of research studies from these research symposia testifies that research concerning mathematics in the early years has gained its place in the research field of mathematics education research. However, there were early years mathematics studies published in journal papers both before 2009 and in parallel with the symposiums. Scrutinising the conference papers, symposium chapters and journal articles reveals that it is evident that most of the studies were 
conducted adopting a qualitative methodology. This was also documented by Levenson et al. (2018), who showed that case studies were conducted, and observations and interviews were made. Moreover, these authors documented that research on the teaching and learning of mathematics in a kindergarten setting was conducted predominantly by adopting a qualitative research strategy. In the current study, we attempted to add to this common qualitative research scope by implementing a quantitative methodology.

Our quantitative approach to mathematics discourse is not unique. Other research has also been conducted in which quantitative data have been drawn upon to analyse students' mathematical discourse. Lewis (2017) conducted a case study of one 19 year old student who suffered from a mathematical learning disability. Theoretically, she drew on Sfard's (2008) theory and her conceptualization of mathematics as a discourse. In her study, Lewis sought to provide a bridge between the student's discourse and the mathematical discourse agreed upon within the mathematics community. Based on quantitative analyses of five videotaped sessions (counting of the student's word use and use of a scale and an area model for fractions in the various mathematics problems she tried to solve), Lewis found that the discourse of the student shifted over time, from the student's own discourse to a more canonical mathematics discourse. Due to this shift, the student became able to solve mathematical problems in which she previously had been unsuccessful.

Another study using quantitative data about mathematical discourse was done by Morgan and Sfard (2016). These researchers analysed the mathematics discourse used in eight final examinations of compulsory schooling in United Kingdom, spanning the years from 1980 to 2011, and they compared this discourse over these years. Morgan and Sfard analysed each examination question with respect to multiple discursive characteristics, e.g., to what extent specialised mathematical language was used, the number of specialised mathematical nouns (such as function and sequence) used, and the frequencies of conjunctions used. This approach enabled them to identify which aspects of mathematical discourse had been transformed, omitted or added over the course of three decades. They found that the discourse used in examinations changed over the years, as follows; "subtle disparities that are nevertheless significant enough to make an important difference in students' vision of mathematics, in their performance and, eventually, in their ability to cope with problems that can benefit from the use of mathematics" (p. 92).

Similarly to our analytical approach, Vogel and Jung (2013) quantified qualitative video data, however from a different perspective. They came up with eleven main categories (with sub-categories) describing the videos analysed. These categories differ from the analytical approach we have taken here, as we explain in the following.
Our analytical approach diverges from the ones of Vogel and Jung (2013), Morgan and Sfard (2016) and Lewis (2017). Thus, our research complements these studies, as we analysed the mathematical discourses as these unfolded in ongoing teaching sessions in kindergarten.

Particularly, we analysed the distribution of time between the kindergarten teacher (KT) and the participating children, and the nature of verbal utterances (mathematical or nonmathematical). Furthermore, we analysed the mathematical engagement nurtured amongst the participating children, i.e., whether the KT's questions and prompts during her teaching engaged none, one or several children to participate verbally in the ongoing discussion.

According to Ryve (2011), the concept of discourse is sparsely defined in a huge number of journal articles focusing on what is called discourse analysis. In many ways, one may view the study of (mathematics) discourse as coinciding with the study of human communication, and "the most unique of this communication is language in use" (Ryve 2011, p. 169). In our study, we draw on the work of Gee (1996), who defined discourse as "a socially accepted association among ways of using language, other symbolic expressions, and 'artifacts', of thinking, feeling, believing, valuing, and acting" (p. 131).

We use the term mathematical discourse in line with Sfard's (2007) use. We thus define a mathematical discourse as a particular type of communication, which features mathematical vocabulary, concepts, metaphors and ideas. Examples are the use of number words (one, two, three...) in counting, discussing properties of geometrical shapes (triangle, quadrilateral, square, pentagon...), and comparing size (small, medium, large). In the current study, we analysed and characterised the emerging mathematical discourses drawing on the framework of Mathematical Discourse in Instruction (MDI), developed by Adler and Ronda (2015).

\section{Mathematical discourse in instruction}

The MDI framework is associated with a sociocultural perspective on learning and development, in particular the focus on language as the main mediating resource we use to communicate, negotiate and collaborate (Rogoff 1990; Vygotsky 1986; Wertsch 1998). As humans, we are social beings and the appropriation process originates from sociocultural contexts in which we participate and contribute with ideas and arguments. Children in a Norwegian kindergarten context participating in a mathematics activity taught by a kindergarten teacher (KT) are thus actively involved in an appropriation process in which they learn to handle and solve mathematical problems with the available cultural tools, for example geometrical shapes, blocks and play money. From a sociocultural perspective, such tools are called mediational 
means, i.e., children interpret and handle their world through the use of such cultural tools. Their thinking and interaction are mediated by such tools, i.e., these processes are emerging from and coloured by the cultures (Norwegian kindergarten and mathematics) in which they act and participate.

The background for the elaboration of the MDI framework for analysing mathematics teaching was a concern for what mathematics students (in South Africa) are supposed to learn. Adler and Ronda's (2015) point of departure was thus the object of learning, i.e., the mathematical concept(s), procedure(s) and/or algorithm(s) the analysed students were meant to appropriate. The MDI framework was further elaborated by emphasising the mediational means that mathematics teachers use in their teaching to bring the object of learning into focus. These generative mechanisms were labelled exemplification, explanatory talk, and learner participation.

Exemplification manifests itself as the mediational means of examples and tasks. Within mathematics teaching, an example serves to represent a larger class of phenomena. It is purposefully used as one particular specimen of the class in order to be able to generalise from that specimen (Zodiak and Zaslavsky 2008). Zodiak and Zaslavsky argued that thoughtful use of examples is imperative for mathematics teachers plausibly to reach the object of learning made explicit for the (sequence of) lesson(s). The mathematical task is the other constituent of exemplification, as students' engagement with mathematics tasks is a highly common enterprise of mathematics teaching. According to Adler and Ronda (2015), a task is: simply what learners are asked to do with the various examples presented" (p. 241). Tasks are used by mathematics teachers to enable their students to demonstrate and reveal their mathematics capabilities.

Explanatory talk is comprised of the mediational means of what is to be done, what is to be known, and how to do it. Such discourse communicates the message of what is valued by the mathematics teacher with respect to the object of learning. The function of explanatory talk is to name and legitimate the focused examples and tasks. The terms naming and legitimation are thus used by Adler and Ronda (2015) to designate the mathematics made explicit for the students to learn. Naming is "the use of words to refer to other words, symbols, images, procedures or relationships" (p. 244). This use of words may be colloquial, nonmathematical everyday language, or it may be mathematical (use of mathematical words, reading strings of mathematical symbols, formal mathematical language). This division is also made explicit by Sfard (2008), who argued that colloquial discourse is an inevitable part of the process of learning. However, it is participation in mathematical discourse that creates opportunities for students to learn mathematics. According to Adler and Ronda (2015), the term legitimation includes four domains, each of them drawing on various criteria to legitimate the mathematics engaged within tasks and examples. These are "the domain of mathematics, nonmathematical domains, the curriculum and the authority of the teacher" (p. 241).

Learner participation is a construct that Adler and Ronda (2015) use to address what the participating learners are invited by the mathematics teacher to say, in particular "whether and how learners have opportunity to speak mathematically and to verbally display mathematical reasoning" (p. 245). It was this generative mechanism that we particularly drew on in our study.

\section{Adaptions of MDI within a kindergarten context}

Mosvold and Fauskanger (2018) used the MDI framework to study student teachers' teaching. However, their research context differs significantly from the kindergarten context and KTs' mathematics teaching. Thus, we adapted and operationalised the MDI framework for our use in this study. Even though MDI was developed based on research in South African classroom settings, we argue that the framework may be purposefully employed in a kindergarten context, as the framework has been subject to slight changes we made when adopting it for our analyses of KTs' teaching of mathematics activities. We drew on the main components of MDI, however with adaptations of component definitions in order for the framework to encompass and fit a Norwegian kindergarten context.

In acknowledging Norwegian kindergartens' enterprise as accommodating a social pedagogy tradition (cf. OECD 2006), we used the term intention when addressing the object of learning. The intention(s) of the mathematical activity comprised the mathematical concept(s) and ideas to be discussed and thus what the children were supposed to learn. This was in line with the framework plan of Norwegian kindergartens (Norwegian Directorate for Education and Training 2017), which does not make children's learning goals explicit.

Concerning the three mediational means exemplification, explanatory talk, and learner participation, we argue the relevance of these as defined by Adler and Ronda (2015), however with some adaptations. Exemplification through examples and tasks was adopted by the KTs studied, however this was done orally through questions and prompts. Explanatory talk was used by both the KTs and the participating children, and as in the analyses, naming, both mathematical and colloquial, was a term describing the discourse within the mathematics teaching in the kindergarten classes. Nevertheless, we did not draw on all facets of the MDI framework with respect to these two mediational means. This was due to contextual and educational differences between mathematics 
teaching in South African schools and mathematics teaching in Norwegian kindergartens.

In this study, in accordance with a sociocultural perspective on learning and development, our stance was that mathematics learning is a collaborative process initiated in communicative and social settings where KTs and children actively participate, interact and argue. Thus, it was vital to analyse children's opportunities to talk. In doing so, our analytical point of departure was the KTs' contributions and the actions generated amongst the children upon the KTs' contributions. These were analysed according to Adler and Ronda's (2015) three levels of learner participation. A Level 1 mathematical discourse is characterised by children contributing with one-word answers to closed questions such as yes/no questions, questions regarding how many things a child has, and questions about shape. Examples are as follows: Are all the edges (of the rectangle) of equal length? How many yellow (bears) were there? Did you count? A Level 2 mathematical discourse is characterised by children contributing with answers to what/how questions by way of phrases or sentences. Examples of this level of discourse are as follows: What is this (a sphere)?, What is your thinking with respect to that one (a cone)?, and How many grapes can you afford? A Level 3 mathematical discourse is characterised by children contributing with answers to why questions, children contributing with mathematical ideas in the discussion, and occasions where the KT revoices children's contributions, confirms children's ideas and answers and asks questions with respect to the children's contributions. Level 3 discourses are exemplified through KT contributions such as the following: Why is that a rectangle? and Why do you have 20 kroner there?

\section{Previous studies of mathematical discourse in early years education}

Mathematical interactions between KTs and children have been studied elsewhere (e.g., Carlsen et al. 2010; Erfjord et al. 2019; Vogel and Jung 2013). However, studies similar to our focus on mathematical discourse in the kindergarten setting are sparse. Relevant studies conducted within a Norwegian kindergarten setting are those by Fosse (2016) and Sæbbe and Mosvold (2016), who focused at the mathematical discourse occurring among KTs and children. Additionally, the study of Dovigo (2016) is of particular interest.

Adopting a commognitive perspective, Sæbbe and Mosvold (2016) studied a KT's discursive acts when he conducted his mathematics teaching, including children playing with Lego bricks. Based on video recordings of the teaching, Sæbbe and Mosvold came up with two core components of the occurring discourse: questioning and affirmation. That is, the KT asked several questions during the teaching as well as affirming the children's responses. The questions initiated a discussion, and in reaction to the children's responses to the questions, the KT followed up with either an affirmation or another question. In total, Sæbbe and Mosvold identified 212 discursive acts by the KT during the mathematical activity. 135 of these were characterised as mathematical (Mathematical affirmation and Other mathematical talk) and 77 were characterised as non-mathematical (General questioning, General affirmation and Other talk).

Fosse (2016), using a Vygotskian perspective, studied four young (about 5 years old) children's mathematical conversations in a Norwegian kindergarten, aiming at characterising the conversation going on as the children collaboratively built a Lego airplane. From analyses of her audio recorded observations, Fosse concluded that mathematical conversations in kindergarten include both mathematical content and conversational structure. The former feature includes characteristics such as being mathematical, reflecting and aiming for further learning. The latter feature includes structuring and interaction among participants. Based on the results of her research, Fosse suggested that mathematical conversations have to involve participants in discussing mathematical concepts, ideas and insights, and these conversations have to promote reflection on their actions and ideas for further actions. She also emphasised that participants' contributions must be valued in their ongoing efforts and interactions.

From a sociocultural point of view, Dovigo (2016) studied the role of argumentation in empowering children's collaboration and problem-solving in six Italian preschool classes (20-25 children in each class) over a period of 10 months. The children were between 3 and 5 years of age, and Dovigo analysed approximately 7000 utterances within teacher-children talk (2419) and peer-talk (4527). The analysis focused both on frequency and extent of argumentations occurring in the conversations. About 4300 of the utterances were characterised as argumentative. Results showed that argumentation was effective in cultivating shared and critical thinking amongst these young children. Moreover, Dovigo argued that this cultivation by way of argumentation contributed to the children's learning development. However, according to Dovigo, this may happen "provided that teachers are able to support them, paying attention to the role of leadership and involvement" (p. 818).

\section{The study: methods, participants and data analysis}

In this study we aimed to characterise qualities of the mathematical discourses occurring in four Norwegian kindergarten classes. We did not explicitly address the issue of children's learning, but rather sought to analyse thoroughly 
the mathematical discourses as these unfolded in the interaction between the KT and the children, making opportunities for the participating children to learn or to individualise the mathematical discourse. Our focus was thus in line with the approach of Adler and Ronda (2015), in which mathematical discourse was revealed in a mathematics classroom, taking both a teacher and a student perspective.

\subsection{The research context}

In Norway, children in kindergartens reflect a mixed inhabitant perspective. Parents can freely choose a kindergarten for their children and usually select a kindergarten close to where they live. The children in the study from the four kindergartens were from rural areas and with small differences in socio-economic background. Thus, this aspect made it possible to juxtapose kindergartens and children, in our case.

The kindergarten classes studied were chosen from participating kindergartens in a research and development project called the Agder Project (AP). The research design of AP was a randomized control trial. All 317 kindergartens in the Agder region were invited to participate. 71 kindergartens volunteered. These were randomly assigned to an experimental group and a control group respectively. An intervention that introduced a comprehensive structured curriculum for 5-year-olds was conducted within kindergartens from the experimental group. The kindergarten teachers in the experimental group received an in-service training course ( $300 \mathrm{~h}$ working load in total) for teaching mathematics to 5 -year-olds. The training consisted of sessions addressing the teaching of early mathematics learning within numeracy, geometry, measurement and statistics, discussions and reflections with respect to implementations of prototype versions of designed activities, as well as teaching and reflections regarding the design principles involved in playful learning and inquiry. These are elaborated in Sect. 5.2. In addition, the course included training in language, social competence and self-regulation. The kindergartens in the control group continued their enterprise as usual.

The intervention was put into action during the children's final year of kindergarten, and the children were involved in four mathematical activities each week. The duration was approximately $45 \mathrm{~min}$ for each activity. The kindergarten classes comprised 6-9 children each. The KTs from the experimental group implemented these activities in our study.

In this paper, we report our analysis of the discourse emerging in two kindergarten classes from the experimental group, called E1 and E2, and two from the control group of the AP, called $\mathrm{C} 1$ and $\mathrm{C} 2$. An aim of our study was thus to juxtapose the qualities of the mathematical discourse unfolding in the experimental versus control kindergarten classes. We were interested in investigating to what extent the in-service training and curriculum had any effects with respect to the characteristics of the mathematical discourse occurring in the kindergarten classes.

\subsection{The curriculum}

The mathematical content of the curriculum of AP comprised numeracy, geometry, measurements and statistics. Within these four mathematical themes, we designed and developed more than 50 activities for the KTs to use in their teaching of the children. The activities were designed to take place both inside and outside the kindergarten. When designing these activities, we drew on two principles, playful learning and inquiry.

In the curriculum, the term playful learning was used to address the importance of play and its close relation to learning. "Playful learning, and not drill-and-practice, engages and motivates children in ways that enhance developmental outcomes and lifelong learning" (Hirsh-Pasek et al. 2009, p. 4). According to Weisberg et al. (2015), playful learning comprises both free play (child-initiated and child-directed play) and guided play (adult-initiated and child-directed play). Both types of play are characterised by children being active and leading the play. In guided play, featuring the mathematical activities included in the curriculum, it is the KT who organises and guides the activities with respect to mathematical intentions for the children's possible learning outcomes. The KT's role is to balance freedom and structure when nurturing the children's interest, curiosity, engagement, and mathematical sense-making. Van Oers (2014) addressed this balance by claiming that " $[\mathrm{t}] \mathrm{he}$ nature of the actions embedded in play can vary with respect to their degree of freedom allowed, as long as the activity as a whole remains a playful activity" (p. 121). We thus argue that guided play is an effective way of teaching mathematics in kindergarten. Weisberg et al. (2015) argued that "guided play is most effective for achieving specific learning goals in areas such as (...) number sense" (pp. 8-9).

The second design principle behind the mathematical activities was inquiry as an approach to mathematics teaching and learning (Jaworski 2005). According to Wells (1999), inquiry includes "a willingness to wonder, to ask questions, and to seek to understand by collaborating with others in the attempt to make answers to them" (p. 121). When adopting an inquiry approach in our design of the activities, we encouraged the KTs to guide their children through the use of questions, through nurturing wondering, and through explorations and investigations. Inquiry as an approach to the learning of mathematics both addresses the importance of children making the mathematics their own through an appropriation process, and the importance of the KT's nurturing of this process. Thus, the designed activities did not explicitly include formal mathematical tasks of the 
type $2+3=_{-}$. Rather, the activities included open-ended explorations and suggested questions and ideas to facilitate children's own wondering and questioning.

As for the two mathematical activities taught by the KTs in the experimental group, they were characterised by these two principles. In E1, the activity was called 'The secret bag'. In this activity, the participating children were to consecutively draw geometrical shapes from an opaque bag. Each child was to explore tactilely, orally describe, and then, in collaboration with the other participating children, conclude what shape (s)he touched. In E2, the activity was called 'The shop'. One child acted as cashier and the other children consecutively acted as customers. One child at a time chose different groceries to buy, and the cashier (sometimes supported by the customer as well as the KT) figured out how much payment was due and how much change needed to be given to the customer. The prices of groceries were within the range of $25 \mathrm{NOK}$.

In $\mathrm{C} 1$, the participating children were involved in a sorting activity. They were to sort a number of plastic bears of three different sizes and four different colours in various ways. Firstly, the children, as a group, were to sort the bears into three groups. Secondly, the children had to count how many bears in each group. Thirdly, the children were to sort the bears according to colour. In parallel with the sorting, the KT questioned the children about their ways of sorting. In $\mathrm{C} 2$, the $\mathrm{KT}$ introduced a pile of cards from which the children consecutively drew cards. The KT and the children discussed and agreed that different suits (clubs, diamonds, hearts, spades) meant different length of steps and the number on the cards indicated the number of each step. The children then competed who would finish an agreed distance first.

\section{Research questions and data corpus}

For the analyses in this study, we collected video data from the mathematics teaching of four kindergarten teachers. The activities involved between three and seven 5-year-old children selected by the KTs. The studied KTs and children from the experimental group (E1 and E2) and KTs and children from the control group ( $\mathrm{C} 1$ and $\mathrm{C} 2$ ) were randomly chosen by drawing lots from children in these two groups of kindergartens. For both groups of KTs and children, participation in this specific study was voluntary.

In each of the two kindergarten classes from the experimental group, the KT taught one of the designed mathematical activities in the curriculum. Thus, we took a pragmatic approach and videotaped the teaching of the mathematical activity that was planned for that particular day according to the curriculum. For the kindergarten classes in the control group, the mathematical activities were chosen solely by the KTs. These teachers were requested in advance by the researchers to teach an activity with mathematics involved. As researchers we thus had no impact concerning the KTs' choices of activities and their mathematical content. Consequently, we analysed four different mathematical activities.

With this theoretical and methodological background, we formulated the following research questions:

1. What characterises the quality of the mathematical discourse in four kindergarten classes where kindergarten teachers and 5-year-old children engage in mathematical learning activities?

2. What are the differences in the mathematical discourses in the two experimental kindergarten classes and the two control kindergarten classes analysed?

\subsection{Analytical approach}

In order to scrutinise the mathematical discourse occurring as part of the KTs' teaching of mathematical activities, we developed an analytical approach to reach our aim of analysing the qualities of the mathematical discourse. Based on our theoretical stance, significant characteristics of mathematical discourse, through which children may learn, are as follows: (1) children's opportunities to contribute with ideas and arguments; (2) the extent and nature of verbal utterances among the participants; and (3) the mathematical engagement nurtured.

With respect to the first characteristic, we investigated the distribution of time among the KT and the children, based on who had the floor and for how long a time. As regards the second characteristic, we analysed the verbal utterances by the KTs, how many and whether these initiated mathematical discourses (M) or non-mathematical discourses (NM). Amongst utterances that initiated what we characterised as non-mathematical were the following: "Now it is your turn", "Please be silent since now it is Erica's turn to answer", and "What did you say, John?" With respect to utterances that initiated mathematical discourses, we included contributions such as: "Are all edges of equal length?", "What shape is this?", "How can you see it is a rectangle?", and "Are you sure?" Verbal utterances were comprised of instructions, argumentations, explanations, questions promoting actions, and questions promoting explanations. The third characteristic was measured by the number of children engaged in the KTs' initiatives. Figure 1 schematically sums up our analytical approach.

Furthermore, we did more profound analyses with respect to the mathematical engagement nurtured by the KTs' requests, questions, and prompts. Based on analyses of these aspects, we characterised the mathematical discourses in each kindergarten class with respect to the three levels 


\begin{tabular}{|c|c|c|c|c|c|c|}
\hline \multicolumn{7}{|c|}{ Distribution of time between the KT and the children } \\
\hline \multicolumn{2}{|l|}{ Who } & \multicolumn{2}{|c|}{ Number of minutes } & \multicolumn{3}{|c|}{ Description of category } \\
\hline \multicolumn{2}{|l|}{ KT active } & & & \multicolumn{3}{|c|}{$\begin{array}{l}\text { Informing, Demonstrating, } \\
\text { Explaining, Exemplifying }\end{array}$} \\
\hline \multicolumn{2}{|c|}{ Dialogic communication } & & & \multicolumn{3}{|c|}{$\begin{array}{l}\text { Questions and prompts from KT and } \\
\text { answers from children }\end{array}$} \\
\hline \multicolumn{2}{|c|}{$\begin{array}{l}\text { Children active } \\
\text { (KT interference tolerated) }\end{array}$} & & & \multicolumn{3}{|c|}{$\begin{array}{l}\text { The children work with concrete } \\
\text { materials, explore mathematical } \\
\text { relationships «on their own» }\end{array}$} \\
\hline \multicolumn{7}{|c|}{$\begin{array}{l}\text { Verbal utterances (questions, instructions, argumentations, explanations) initiating } \\
\text { mathematical and non-mathematical discourses }\end{array}$} \\
\hline & \multicolumn{3}{|c|}{ Mathematical (M) (\#) } & \multicolumn{3}{|c|}{ Non-mathematical (NM) (\#) } \\
\hline \multicolumn{7}{|l|}{ KT } \\
\hline \multicolumn{7}{|c|}{ Mathematical engagement nurtured } \\
\hline \multicolumn{2}{|l|}{ Initiatives from KT } & Child 1 & Child 2 & Child 3 & Child 4 & Child 5 \\
\hline \multicolumn{7}{|l|}{1} \\
\hline \multicolumn{7}{|l|}{2} \\
\hline \multicolumn{7}{|l|}{$\ldots$} \\
\hline $\mathrm{N}$ & & & & & & \\
\hline
\end{tabular}

Fig. 1 The analytical approach to quantification of qualitative data

of mathematical discourse launched by Adler and Ronda (2015).

\section{Analysis and results}

Before delving into the analysis of the mathematical discourse in the four kindergarten classes, it is crucial to comment on two issues. First, the total length of the activities in the four kindergarten classes respectively, varied considerably. The two activities orchestrated in the kindergarten classes from the experimental group lasted approximately $22 \mathrm{~min}$ and $32 \mathrm{~min}$. The activities in the kindergarten classes from the control group lasted approximately $11.5 \mathrm{~min}$ and $8.5 \mathrm{~min}$. We thus hypothesise that the KTs from the experimental group were more capable of teaching mathematics to the children as they kept the mathematical discourse going for a much longer time compared with the KTs from the control group. Furthermore, as mathematical learning is a process emerging over time and from thorough discussions (cf. Rogoff 1990; Vygotsky 1986; Wertsch 1998), we hypothesised that the children's learning opportunities within the activities in E1 and E2 were greater than in $\mathrm{C} 1$ and $\mathrm{C} 2$. Second, the activities were also different concerning the extent to which they promoted mathematical engagement and at what level (cf. Adler and Ronda 2015) the promoted discourse thus was. These issues were important to take into account when juxtaposing the four kindergarten classes.

With respect to the distribution of time, we observed small differences amongst the kindergarten classes. In the following table (Table 1), the amount of time used with respect to the three categories is presented (E1 and E2Kindergarten classes from the experimental group, $\mathrm{C} 1$ and C2-Kindergarten classes from the control group):

In E2 there was more time (approx. 38\%), compared to the three others, devoted for the participating children to be active. We argue that this was due to the fact that the children were playing at a shop in which they took roles as customers and cashiers without much interference from the KT. In $\mathrm{C} 1$ there was relatively most time (approx. 61\%) devoted to dialogic communication. This was, we argue, due to the activity being about sorting and ordering plastic bears in which the KT and the participating children collaborated a lot. In $\mathrm{C} 2$ there was relatively most time (approx. $41 \%$ ) in which the KT was active. We argue that this was due to the fact that the activity was about drawing cards from a deck, where each card meant a specific, physical movement and a number concerning this movement. The KT and the children agreed that spades meant long steps, clubs meant short steps, hearts meant medium steps and diamonds meant jumping. The KT was drawing the cards and commenting while the children were taking a number of long/short/medium steps or jumps according to the number and the sort of each card. From these observations and analyses we argue that the distribution of time was subject to the nature of the activities taught. From Table 1 we cannot conclude that there were differences between the two groups of kindergarten classes with respect to distribution of time. Nevertheless, we observe that the mathematics teaching in the kindergarten classes from the experimental kindergartens was more extensive with respect to total time than the teaching in the kindergarten classes from the control kindergartens.

In Table 2, we have included all four kindergarten classes (E1, E2, C1 and C2) and filled each cell with appropriate

Table 1 Distribution of time in the kindergarten classes

\begin{tabular}{|c|c|c|c|c|c|c|c|c|c|}
\hline \multicolumn{10}{|c|}{ Distribution of time between the KT and the children } \\
\hline \multirow[t]{2}{*}{ Who } & \multirow[t]{2}{*}{ Description of category } & \multicolumn{2}{|l|}{ E1 } & \multicolumn{2}{|l|}{ E2 } & \multicolumn{2}{|l|}{$\mathrm{C} 1$} & \multicolumn{2}{|l|}{$\mathrm{C} 2$} \\
\hline & & Time $^{a}$ & $\%$ & Time $^{\mathrm{a}}$ & $\%$ & Time $^{\mathrm{a}}$ & $\%$ & Time $^{\mathrm{a}}$ & $\%$ \\
\hline KT active & Informing, Demonstrating, Explaining, Exemplifying & $7: 16$ & 33 & $8: 52$ & 28 & $2: 11$ & 19 & $3: 27$ & 41 \\
\hline Dialogic communication & Questions and prompts from $\mathrm{KT}$ and answers from children & $10: 54$ & 49 & $10: 55$ & 34 & $6: 58$ & 61 & 2:02 & 24 \\
\hline Children active & $\begin{array}{l}\text { The children work with concrete materials, explore math- } \\
\text { ematical relationships "on their own" }\end{array}$ & $4: 11$ & 19 & $11: 54$ & 38 & $2: 16$ & 20 & $3: 01$ & 35 \\
\hline
\end{tabular}

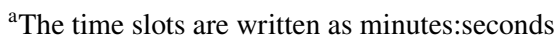


Table 2 Distribution and characteristics of KTs' verbal utterances
Verbal utterances (questions, instructions, argumentations, explanations) initiating mathematical and nonmathematical discourses

\begin{tabular}{|c|c|c|c|c|c|c|c|c|}
\hline & \multicolumn{2}{|l|}{ E1 } & \multicolumn{2}{|l|}{ E2 } & \multicolumn{2}{|l|}{ C1 } & \multicolumn{2}{|c|}{$\mathrm{C} 2$} \\
\hline & M & NM & M & $\mathrm{NM}$ & M & NM & M & NM \\
\hline KT & 84 & 74 & 222 & 146 & 69 & 34 & 41 & 27 \\
\hline
\end{tabular}

numbers with respect to verbal utterances made by the KTs respectively, as well as characterising the utterances as mathematical (M) and non-mathematical (NM).

With respect to the KTs' questions, prompts and comments that initiated mathematical discourses, the children responded appropriately on most occasions. However, based on the nature of the KTs' prompts, the children's responses were in some cases mathematical and in a few cases non-mathematical. As indicated in Table 3, what we focused on was the utterances from the KTs coded as initiating mathematical discourses. Based on the KTs' mathematical utterances, we counted the number of utterances from the children with respect to each of the KTs' prompts. These numbers are represented in the row called 'Children'. Table 3 presents the number of utterances from the children in response to the KT's prompts initiating mathematical discourses in each of the kindergarten classes.

Typically, the mathematical discourses in the kindergarten classes unfolded as in the following example:

KT Shows a rectangular shape.

Eric Rectangle.

KT What did you say, Eric?

Eric Rectangle.

KT Rectangle. How do you know that?

Eric There are four edges.

Nina Quadrilateral.

KT Four edges.
Table 3 Number of child responses to the KTs' prompts

Table 4 Number of contributions distributed over the children
This example from one of the kindergarten classes, E1, illustrates that the KTs contributed approximately every second utterance in the discourse. It also testifies the significant role the $\mathrm{KT}$ plays in pushing the mathematical discussion forward, through questioning and affirmation.

Based on these contributions to the ongoing discussions, we looked at who and how many children were responding to the KTs' utterances (see Table 4). The children's contributions responding to the KTs' questions and prompts were both of mathematical and non-mathematical nature. Table 4 shows that all children in each of the kindergarten classes contributed to the ongoing mathematical discussions. All participating children were thus mathematically engaged in the activities. Thus, in this table, we are not comparing the number of contributions in the four kindergarten classes. Rather, we observe that all four KTs involved all their children in the mathematical discourse, however to a varying degree. Notice that who is called child 1 in kindergarten class E1 is not the same child as who is called child 1 in kindergarten class E2, etc. Child 1 is thus a label used for the first child who spoke in each of the kindergarten classes, Child 2 is a label used for the second child who spoke, etc. The grey cells in Table 4 (and Table 5) indicate that there were a different number of children participating in each of the kindergarten classes. For instance, there was no child labelled Child 6 in E1, E2 and C2, simply because there were not that many children participating in these kindergarten classes.

To further analyse the unfolding mathematical discourse, we also scrutinised the number of children responding to each of the KTs' questions, comments and prompts. Thus, we further analysed the mathematical engagement nurtured among the participating children (see Table 5). In Table 5 we see, for example, that in E1 there were nine occasions where no children responded to the KT's utterances, on 42

\begin{tabular}{lllll}
\hline \multicolumn{4}{l}{ Verbal utterances } \\
\hline & E1 & E2 & C1 & C2 \\
\hline KT & 84 & 222 & 69 & 41 \\
Children & 108 & 259 & 97 & 43 \\
\hline
\end{tabular}

\section{the children}

\begin{tabular}{|c|c|c|c|c|c|c|c|c|c|}
\hline & Child 1 & Child 2 & Child 3 & Child 4 & Child 5 & Child 6 & Child 7 & $>1$ & Sum $^{\mathrm{a}}$ \\
\hline \multicolumn{10}{|c|}{ Number of children's responses upon the KT's utterances initiating mathematical discourses } \\
\hline E1 & 40 & 20 & 16 & 14 & 12 & & & 6 & 108 \\
\hline E2 & 76 & 69 & 67 & 45 & & & & 2 & 259 \\
\hline $\mathrm{C} 1$ & 32 & 20 & 11 & 10 & 8 & 8 & 6 & 2 & 97 \\
\hline $\mathrm{C} 2$ & 18 & 15 & 7 & & & & & 3 & 43 \\
\hline
\end{tabular}

${ }^{a}$ These numbers are the sum of the mathematical and the non-mathematical utterances of the children 
Table 5 Number of children mathematically engaged

\begin{tabular}{lrrrrrrrrrr}
\hline $\begin{array}{l}\text { \# children } \\
\text { engaged }\end{array}$ & \multicolumn{1}{l}{1} & 1 & 2 & 3 & 4 & 5 & 6 & 7 & $\begin{array}{l}\text { Unquantifi- }_{\text {able }} \\
\text { abum }\end{array}$ \\
\hline E1 & 9 & 42 & 23 & 3 & 1 & 0 & & & 6 & 84 \\
E2 & 8 & 163 & 46 & 4 & 0 & & & & 1 & 222 \\
C1 & 10 & 31 & 16 & 7 & 3 & 0 & 0 & 0 & 2 & 69 \\
C2 & 4 & 31 & 5 & 0 & & & & & 1 & 41 \\
\hline
\end{tabular}

${ }^{a}$ Unquantifiable, here and in Table 6, 7, 8 and 9, means that from the videotapes it was not possible to distinguish how many children were responding

${ }^{\mathrm{b}}$ These numbers correspond to the number of mathematical utterances made by the KTs during the activities (see Table 2)

\begin{tabular}{lrrrrrr}
\hline \# of children engaged & \multicolumn{1}{c}{1} & 2 & 3 & 4 & $\begin{array}{l}\text { Unquantifi- } \\
\text { able }\end{array}$ & Sum \\
\hline \# of mathematical discourses at Level 1 & 30 & 11 & 1 & 0 & 1 & 43 \\
\# of mathematical discourses at Level 2 & 12 & 9 & 2 & 2 & 4 & 29 \\
\# of mathematical discourses at Level 3 & 1 & 2 & 0 & 0 & 0 & 3 \\
Total & 43 & 22 & 3 & 2 & 5 & 75 \\
\hline
\end{tabular}

Table 6 Number of children involved versus Levels of mathematical discourse in E1

Table 7 Number of children involved versus Levels of mathematical discourse in E2

\begin{tabular}{lrrrrrr}
\hline \# of children engaged & 1 & 2 & 3 & 4 & $\begin{array}{l}\text { Unquantifi- } \\
\text { able }\end{array}$ & Sum \\
\hline \# of mathematical discourses at Level 1 & 126 & 34 & 2 & 0 & 1 & 163 \\
\# of mathematical discourses at Level 2 & 32 & 11 & 2 & 0 & 0 & 45 \\
\# of mathematical discourses at Level 3 & 5 & 1 & 0 & 0 & 0 & 6 \\
Total & 163 & 46 & 4 & 0 & 1 & 214 \\
\hline
\end{tabular}

occasions one child responded, etc. In $\mathrm{C} 1$ there were ten occasions where no children responded to the KT's utterances, 31 occasions where one child responded, etc.

In order to analyse the mathematical discourse occurring in the four kindergarten classes in depth, we further scrutinised each of the mathematical contributions from the KTs against the mathematical engagement nurtured. This mathematical engagement was analysed in accordance with the three levels of mathematical discourse launched in the MDI framework (cf. Adler and Ronda 2015) described in Sect. 3. These analyses are presented taking one kindergarten class at a time. The number indicating the total sum (lower right cell) is the total number of KT mathematical utterances minus the cases where no child was engaged. That is, for example, in E1, the KT made 84 mathematical contributions. Out of these, there were 9 occasions where no children responded to the KT's contribution. We thus arrived at 84 $-9=75$ mathematical utterances that were of interest. In E1 we obtained the following result ${ }^{1}$ communicated in Table 6:

\footnotetext{
1 The analysis behind this result was presented in Erfjord, et al. (2019), but reanalysed for the purpose of this study.
}

In the second kindergarten class from the experimental group, we obtained the following results (see Table 7) with respect to Levels of mathematical discourse:

Regarding the first kindergarten class from the control group, we obtained the following results (see Table 8) with respect to Levels of mathematical discourse:

With respect to the second kindergarten class from the control group, we obtained the following results (see Table 9) with respect to Levels of mathematical discourse:

From these tables (Tables 6, 7, 8, 9), we observe that generally few children were mathematically engaged in the discussions. Moreover, the numbers signify that the mathematical discourses were overwhelmingly dominated by Level 1 discourses according to the MDI framework (cf. Adler and Ronda 2015).

\section{Discussion and conclusion}

In this study, we set out to come up with answers to the following two research questions: What characterises the quality of the mathematical discourse in four kindergarten classes where kindergarten teachers and 5-year-old 
Table 8 Number of children involved versus Levels of mathematical discourse in $\mathrm{C} 1$

\begin{tabular}{lrrrrrrrrr}
\hline \# of children engaged & 1 & 2 & 3 & 4 & 5 & 6 & 7 & $\begin{array}{c}\text { Unquantifi- } \\
\text { able }\end{array}$ & Sum \\
\hline \# of mathematical discourses at Level 1 & 26 & 12 & 6 & 1 & 0 & 0 & 0 & 3 & 48 \\
\# of mathematical discourses at Level 2 & 5 & 3 & 1 & 1 & 0 & 0 & 0 & 0 & 10 \\
\# of mathematical discourses at Level 3 & 0 & 1 & 0 & 0 & 0 & 0 & 0 & 0 & 1 \\
Total & 31 & 16 & 7 & 2 & 0 & 0 & 0 & 3 & 59 \\
\hline
\end{tabular}

Table 9 Number of children involved versus Levels of mathematical discourse in $\mathrm{C} 2$

\begin{tabular}{llllll}
\hline \# of children engaged & 1 & 2 & 3 & Unquantifiable & Sum \\
\hline $\begin{array}{l}\text { \# of mathematical discourses at } \\
\text { Level 1 }\end{array}$ & 28 & 5 & 0 & 1 & 34 \\
$\begin{array}{l}\text { \# of mathematical discourses at } \\
\text { Level 2 }\end{array}$ & 3 & 0 & 0 & & 3 \\
$\begin{array}{l}\text { \# of mathematical discourses at } \\
\text { Level 3 }\end{array}$ & 0 & 0 & 0 & & 0 \\
\begin{tabular}{l} 
Total \\
\hline
\end{tabular} & 31 & 5 & 0 & 1 & 37 \\
\hline
\end{tabular}

children engage in mathematical learning activities? And what are the differences in the mathematical discourses in the two experimental kindergarten classes and the two control kindergarten classes analysed? We discuss these questions one at a time.

Concerning the characteristics of the mathematical discourse in the four kindergarten classes, our first finding is that the KTs in all four kindergarten classes were actively guiding the mathematical discussions going on. Table 1 indicates that for more than $60 \%$ of the time all the KTs were very active, either in solely having the word or being involved in dialogic communication with the participating children. Table 3 indicates that the KTs contributed approximately every second utterance in the discourses. Thus, the KTs took a leading role, guiding the children in their mathematical reasoning through questions and argumentative prompts. In general, this issue is also commented on by Dovigo (2016). He argued that the teacher's role is fundamental in children's development of shared and critical thinking. Based on this and our theoretical stance (cf. Rogoff 1990; Wertsch 1998), we conclude that the KTs are vital in order for the children to appropriate mathematical concepts and ideas.

Our second finding is that the KTs' contributions to the ongoing discussion are divided between mathematical and non-mathematical utterances (cf. Table 2). This division has been documented by Sæbbe and Mosvold (2016) and Fosse (2016) as well. Even though many of the KTs' utterances are characterised as non-mathematical, a huge proportion of these are contextual and thus necessary in order to keep the mathematical discussion going. Both the mathematical and non-mathematical utterances keep the mathematics teaching focused on the object of learning (cf. Adler and Ronda, 2015).

The third characteristic of the mathematical discourses in the four kindergarten classes is that all children are actively participating (cf. Table 4). However, the typical pattern is that one or two children respond to the KTs' prompts (cf. Table 5). We do not find this result surprising, as earlier studies also have documented that the mathematical discourse in Norwegian kindergarten classes is characterised by such turn-taking (cf. Carlsen et al. 2010; Sæbbe and Mosvold 2016). We thus conclude that all the children are mathematically nurtured in these activities, even though some children are more active than others.

Concerning the differences in the mathematical discourses in the two experimental kindergarten classes and the two control kindergarten classes, our analyses show the following: From our request to the KTs that they teach mathematics to their 5-year-olds, we found that the KTs from the experimental group taught mathematics for a much longer time than the KTs from the control group. Table 1 shows that the activities in E1 and E2 lasted significantly longer. This difference in length of activity may be a result of the fact that the KTs in E1 and E2 participated in the in-service training and had the curriculum available. These KTs were exposed to intensive discussions with respect to ways of mathematically engaging children in activities. These aspects thus seem to indicate that the in-service training resulted in sustained mathematical discussions. Moreover, we also observe (cf. Table 3) that the number of contributions from the children in E1 and E2 is larger. These children thus took the opportunity to contribute mathematically. We therefore hypothesise that the mathematical learning opportunity is larger for the children participating in E1 and E2 compared with the children in C1 and C2 (cf. Rogoff 1990; Vygotsky 1986).

The most significant difference between the two kindergarten classes in the experimental group, and the two kindergarten classes in the control group, concerns the Levels of discourse (cf. Adler and Ronda 2015). Tables 6, 7,8 and 9 show that the number of discourses at Level 2 and Level 3 are larger in E1 (32/75, 43\%) and E2 (51/214, $24 \%)$ than in $\mathrm{C} 1(11 / 59,19 \%)$ and $\mathrm{C} 2(3 / 37,8 \%)$, both in terms of absolute numbers and proportionally. According to Sfard (2007), "Learning mathematics may now be defined 
as individualizing mathematical discourse, that is, as the process of becoming able to have mathematical communication not only with others, but also with oneself" (p. 573). We thus conclude that the children participating in E1 and E2 may have more extensive opportunities to individualise the mathematical discourse occurring than the children participating in $\mathrm{C} 1$ and $\mathrm{C} 2$. Nevertheless, with respect to the mathematical learning opportunities of the discourses occurring in the kindergarten classes, we would have liked to observe mathematical discourses at Level 3 engaging as many children as possible. From the conducted analyses, we rarely observed this.

\section{Implications}

Our results document that the KTs were capable of involving all the children in the activities. Nevertheless, the children participated in the activities to a varying degree. The joint activity and mutual engagement successfully orchestrated by the KTs in this study, document valuable and beneficial ways of teaching mathematics to pre-school children.

As observed in Table 1, the mathematics teaching sessions in the kindergarten classes from the experimental group lasted longer than the teaching sessions in the kindergarten classes from the control group. We hypothesise that one reason why the observed mathematics teaching sessions in E1 and E2 lasted longer is due to these KTs' participation in the professional development program and use of a curriculum that pinpointed playful learning and an inquiry approach to the mathematics. This observation implies that participation in in-service training with the curriculum used in this study may result in longer mathematics teaching sessions in which the children may participate. We argue that being exposed to relatively long mathematics teaching sessions may establish more extensive mathematics learning opportunities for the children.

Our analyses also document that the KTs from the experimental group were more capable of engaging the children in substantial mathematical discourses than the ones from the control group. As these KTs participated in a professional development program, we argue that our findings imply that in-service training focused on mathematics teaching for preschool children may result in richer mathematical activities as well as more profound engagement in discussions of mathematical concepts and ideas.

A methodological implication from our study is that our analytical approach as regards qualities of mathematical discourses (opportunities to contribute with ideas and arguments, extent and nature of verbal utterances, mathematical engagement nurtured) unfolding in kindergarten classes, complemented by the MDI framework of Adler and Ronda (2015), supplements qualitative approaches to discourse analysis. Our quantitative approach to analyse qualities of mathematical discourses (measuring distribution of time between participants, counting verbal utterances of participants, counting the number of responses, counting the number of discourses with respect to MDI Levels) supplements more common analyses of classroom transcripts in mathematics education research.

One issue not explicitly revealed in our analysis is that on several occasions, the KTs initiated what we argue encompasses opportunities to become a mathematical discourse at Level 3 (cf. Adler and Ronda 2015). However, due to the KTs' eagerness and uptake of children's contributions, these opportunities were not often realised. This result implies that patience and refraining from taking actions are valuable and crucial facets of mathematics teaching in kindergartens.

Acknowledgements Open Access funding provided by University of Agder. The research reported was conducted within the Agder project. The Agder project is funded by the Research Council of Norway (NFR no. 237973), The Sørlandet Knowledge Foundation, The Development and Competence Fund of Aust-Agder, Vest-Agder County, Aust-Agder County, University of Agder and University of Stavanger.

Open Access This article is licensed under a Creative Commons Attribution 4.0 International License, which permits use, sharing, adaptation, distribution and reproduction in any medium or format, as long as you give appropriate credit to the original author(s) and the source, provide a link to the Creative Commons licence, and indicate if changes were made. The images or other third party material in this article are included in the article's Creative Commons licence, unless indicated otherwise in a credit line to the material. If material is not included in the article's Creative Commons licence and your intended use is not permitted by statutory regulation or exceeds the permitted use, you will need to obtain permission directly from the copyright holder. To view a copy of this licence, visit http://creativecommons.org/licenses/by/4.0/.

\section{References}

Adler, J., \& Ronda, E. (2015). A framework for describing mathematics discourse in instruction and interpreting differences in teaching. African Journal of Research in Mathematics, Science and Technology Education, 19(3), 237-254. https://doi.org/10.1080/10288 457.2015.1089677.

Carlsen, M., Erfjord, I., \& Hundeland, P. S. (2010). Orchestration of mathematical activeities in the kindergarten: The role of questions. In V. Durand-Guerrier, S. Soury-Lavergne, \& F. Arzarello (Eds.), Proceedings of the sixth congress of the European Society for Research in Mathematics Education. January $28^{\text {th }}-$ February 1st 2009 (pp. 2567-2576). Lyon: Institut National De Recherche Pédagogique.

Dovigo, F. (2016). Argumentation in preschool: A common ground for collaborative learning in early childhood. European Early Childhood Education Research Journal, 24(6), 818-840. https://doi. org/10.1080/1350293X.2016.1239327.

Erfjord, I., Carlsen, M., \& Hundeland, P. S. (2019). Characterising the mathematical discourse in a kindergarten. In U. T. Jankvist, M. van den Heuvel-Panhuizen, \& M. Veldhuis (Eds.), Proceedings of the eleventh congress of the European Society for Research in 
Mathematics Education, (pp. 2257-2264). Utrecht: Freudenthal Group \& Freudenthal Institute, Utrecht University and ERME.

Fosse, T. (2016). What characterises mathematical conversations in a Norwegian kindergarten? Nordic Studies in Mathematics Education, 21(4), 135-153.

Gee, J. P. (1996). Social linguistics and literacies: Ideology in discourses (2nd ed.). London: Falmer Press.

Hirsh-Pasek, K., Golinkoff, R. M., Berk, L. E., \& Singer, D. G. (2009). A mandate for playful learning in preschool: Presenting the evidence. New York: Oxford University Press.

Jaworski, B. (2005). Learning communities in mathematics: Creating an inquiry community between teachers and didacticians. Research in Mathematics Education, 7(1), 101-119. https://doi. org/10.1080/14794800008520148.

Levenson, E. S., Bartolini Bussi, M. G., \& Erfjord, I. (2018). Early years mathematics. In T. Dreyfus, M. Artigue, D. Potari, S. Prediger, \& K. Ruthven (Eds.), Developing research in mathematics education: Twenty years of communication, cooperation and collaboration in Europe (pp. 106-114). New York: Routledge.

Lewis, K. E. (2017). Designing a bridging discourse: Re-mediation of a mathematical learning disability. Journal of the Learning Sciences, 26(2), 320-365. https://doi.org/10.1080/10508 406.2016.1256810.

Morgan, C., \& Sfard, A. (2016). Investigating changes in highstakes mathematics examinations: A discursive approach. Research in Mathematics Education, 18(2), 92-119. https://doi. org/10.1080/14794802.2016.1176596.

Mosvold, R., \& Fauskanger, J. (2018). Opportunities and challenges of using the MDI framework for research in Norwegian teacher education. In E. Norén, H. Palmér, \& A. Cooke (Eds.), Nordic research in mathematics education. Papers of NORMA 17. The Eight Nordic Conference on Mathematics Education. Stockholm, May 30-June 2, 2017 (pp. 209-219). Göteborg: Svensk förening för MatematikDidaktisk Forskning.

Norwegian Directorate for Education and Training (2017). Framework plan for Norwegian kindergartens. Contents and tasks. https:// www.udir.no/globalassets/filer/barnehage/rammeplan/frameworkplan-for-kindergartens2-2017.pdfhttps://www.udir.no/globalasse ts/filer/barnehage/rammeplan/framework-plan-for-kindergartens22017.pdf. Accessed 04 June 2019.

OECD (2006). Starting strong II: Early childhood education and care. Organisation for Economic Co-operation and Development.

Rogoff, B. (1990). Apprenticeship in thinking. Cognitive development in social context. New York: Oxford University Press.
Ryve, A. (2011). Discourse research in mathematics education: A critical evaluation of 108 journal articles. Journal for Research in Mathematics Education, 42(2), 167-199.

Sfard, A. (2007). When the rules of discourse change, but nobody tells you: Making sense of mathematics learning from a commognitive standpoint. Journal of the Learning Sciences, 16(4), 565-613. https://doi.org/10.1080/10508400701525253.

Sfard, A. (2008). Thinking as communicating: Human development, development of discourses, and mathematizing. Cambridge: Cambridge University Press.

Sæbbe, P. E., \& Mosvold, R. (2016). Initiating a conceptualization of the professional work of teaching mathematics in kindergarten in terms of discourse. Nordic Studies in Mathematics Education, 21(4), 79-93.

van Oers, B. (2014). The roots of mathematising in young children's play. In U. Kortenkamp, B. Brandt, C. Benz, G. Krummheuer, S. Ladel, \& R. Vogel (Eds.), Early mathematics learning. Selected papers of the POEM 2012 conference (pp. 111-123). New York: Springer.

Vogel, R., \& Jung, J. (2013). Videocoding-A methodological research approach to mathematical activities of kindergarten children. In B. Ubuz, Ç. Haser, \& M. A. Mariotti (Eds.), Proceedings of the eighth congress of the European Society for Research in Mathematics Education (pp. 2248-2257). Ankara: Middle East Technical University.

Vygotsky, L. S. (1986). Thought and language. Cambridge: The M. I. T. Press.

Weisberg, D. S., Kittredge, A. K., Hirsh-Pasek, K., Golinkoff, R. M., \& Klahr, D. (2015). Making play work for education. Phi Delta Kappan, 96(8), 8-13.

Wells, G. (1999). Dialogic inquiry: Towards a sociocultural practice and theory of education. Cambridge: Cambridge University Press.

Wertsch, J. V. (1998). Mind as action. New York: Oxford University Press.

Zodiak, I., \& Zaslavsky, O. (2008). Characteristics of teachers' choice of examples in and for the mathematics classroom. Educational Studies in Mathematics, 69(2), 165-182. https://doi.org/10.1007/ s10649-008-9140.

Publisher's Note Springer Nature remains neutral with regard to jurisdictional claims in published maps and institutional affiliations. 